\title{
Nutrient intakes in European elderly populations: Comparison with recommendations
}

\author{
C.H.S. Ruxton ${ }^{1}$ and E. Derbyshire ${ }^{2}$ \\ ${ }^{1}$ Freelance Dietitian, Nutrition Communications, 26 East Road, Cupar, KY15 4HQ, UK and ${ }^{2}$ Freelance Nutritionist, 65 \\ Mayfair Avenue, Worcester Park, Surrey, UK
}

Elderly people are often at risk of inadequate nutritional intake ${ }^{(1)}$. Contributing factors include sensory impairment, poor dentition, reduced appetite and limited food access ${ }^{(2)}$. As nutrition impacts on chronic disease risk, as well as being a factor in length of hospital stay, reported wellbeing, and recovery from acute illness, it is important to understand where the deficits in older people's nutrition lie.

PubMed and Internet searches were done using key terms "European" + "Dietary Survey" + "Fatty acid/Nutrient/Micronutrient". For data to be included, a full report translated into English was required plus fatty acid data presented as percentage daily energy.

The results from two Europe-wide and five country-specific surveys showed that saturated fat intakes as a proportion of energy were above $10 \%$ (range $12-14.5 \%$ ) while $n 3$ polyunsaturated fatty acid (PUFA) intakes were within the acceptable macronutrient distribution range of 2.5-9\% daily energy. Long chain $n 3$ PUFA intakes missed targets in the German and Finnish surveys. Other surveys did not report these data. Mean vitamin and mineral intakes as a proportion of recommendations were reported in six surveys - see below:

\begin{tabular}{|c|c|c|c|c|c|c|c|c|c|}
\hline Ref & Age & Gender & Vit D & Folate & $\mathrm{Ca}$ & $\mathrm{Mg}$ & $\mathrm{K}$ & $\mathrm{Fe}$ & $\mathrm{Zn}$ \\
\hline 3 & $50-64$ y & M & - & 148 & 130 & - & - & 135 & - \\
\hline UK & & $\mathrm{F}$ & - & 123 & 110 & - & - & 110 & - \\
\hline 4 & $\geqslant 65 \mathrm{y}$ & M & 38 & 148 & 135 & 90 & 88 & 125 & 97 \\
\hline UK & & $\mathrm{F}$ & 29 & 120 & 113 & 82 & 74 & 109 & 109 \\
\hline 5 & $50-64$ y & M & - & 144 & 127 & 85 & 85 & 133 & 100 \\
\hline \multirow[t]{3}{*}{ UK low income } & $\geqslant 65 \mathrm{y}$ & $\mathrm{F}$ & - & 129 & 119 & 76 & 75 & 117 & 87 \\
\hline & M & 34 & 112 & 107 & 74 & 69 & 99 & 99 & \\
\hline & $\mathrm{F}$ & 26 & 110 & 104 & 70 & 65 & 103 & 98 & \\
\hline 6 & $\geqslant 70 \mathrm{y}$ & $\mathrm{M} / \mathrm{F}$ & 16 & - & 79 & 67 & - & 102 & - \\
\hline France & & & & & & & & & \\
\hline 7 & $74-79 y$ & M & - & - & - & - & - & {$[7 \cdot 2]^{*}$} & - \\
\hline Europe & & $\mathrm{F}$ & - & - & - & - & - & {$[23 \cdot 3]$} & - \\
\hline
\end{tabular}

y, year; * data show percentage below recommendation

The limited data on elderly populations suggest that average intakes of micronutrients are mostly satisfactory except for vitamin D, magnesium, potassium and zinc. Iron can be low or borderline in older groups. Fatty acid proportions are typically not in line with recommendations. Further work should identify sub-groups with inadequate nutrient intakes. It is worth noting that current UK policy states that housebound people and those aged $\geqslant 65$ y should take a daily vitamin D supplement of 10 mcg. However, only $42 \%$ of older people take any form of dietary supplement, indicating a need for better communication around vitamin $\mathrm{D}^{(3)}$.

This work was funded by the Health Supplements Information Service (www.hsis.org) which is supported by an unrestricted grant from the Proprietary Association of GB.

1. van Bokhorst-de van der Schueren MA et al. (2013). Clin Nutr 32, 1007-1011.

2. Ruxton CHS et al. (2015). J Hum Nutr Diet doi: 10.1111/jhn.12335.

3. Bates B et al. (2014). National Diet and Nutrition Survey years 1-4. London: FSA. 